\title{
CORRUGATED TUBE (PA11) INSERTION ON A HYDRAULIC PORT (FIR-TREE)
}

\author{
Nathan Fonte Boa, Marcos Paulo Del Passo \\ Robert Bosch Ltda \\ E-mails: nathan.boa@br.bosch.com,marcos.passo@br.bosch.com
}

\begin{abstract}
CAE (Computer Aided Engineering) tools are very widely used in the automotive industry. In fact, their use has enabled the automakers to reduce product development cost and time while improving the safety, comfort, and durability of the vehicles they produce. The predictive capability of CAE tools has progressed to the point where much of the design verification is now done using computer simulations rather than physical prototype testing.

Even though there have been many advances in CAE, and it is widely used in the engineering field, physical testing is still used as a final confirmation for subsystems due to the fact that CAE cannot predict all variables in complex assemblies. (http://en.wikipedia.org/wiki/Computer-aided_engineering)
\end{abstract}

During the evaluation of some assembly process, sometimes it is not possible to have enough or even representative samples that can be used on a Design of Experiments (DOE). In these cases, simulations can be performed to determine qualitative influence and interactions between several factors.

This paper aims to propose a simulation way to evaluate the insertion assembly process of a PA11 tube in a fir tree hydraulic port and also the main design factors that could influence on this process.

\section{INTRODUCTION}

In the past, the companies determined their product prices according to the following formula: Cost + Profit $=$ Price, it means that accounting department determined the cost based on the accounting principles considering a profit margin. The price was forwarded to customer who due to low number of competitors often paid the bill. Nowadays due to increase of number of competitors the equation is determined as following: Price (fixed) - Cost $=$ Profit, it means that the price is fixed being determined by market. The Lean system production has as one of its principles the cost reduction totally aligned with decrease of production waste. (DENNIS, 2008).

This study will present how mistakes during the product development (which can result in material loss and waste of time raising the cost) can be foreseen during the development project phase. 
The study is based on fuel pump module (FPM) production. Main task of FPM is delivering of fuel to engine in given quantity and with given pressure in every condition. FPM is placed inside the tank.

The line module production is divided in many work packages where each package is responsible to specific component assembly/testing. One of these components used in assembly process is the PA11 corrugated tube. The tube serves as a transport of fuel from pump to the flange and car engine.

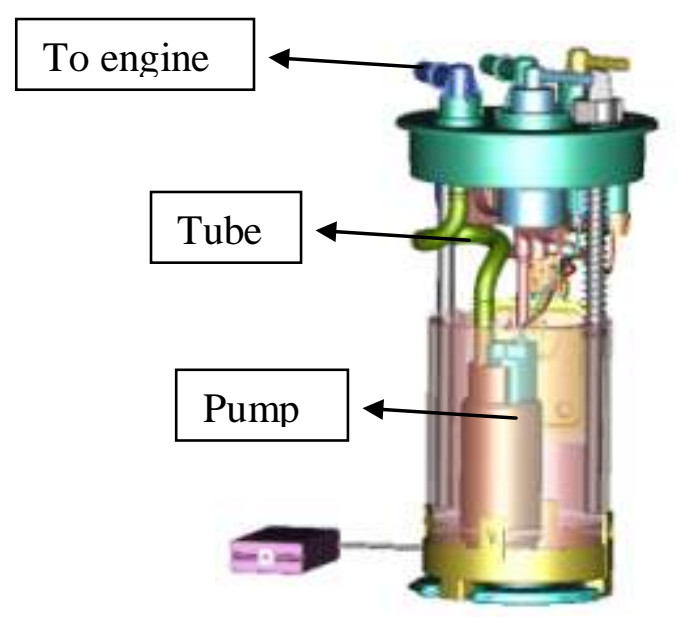

Figure 1. Fuel pump module description

On the assembly station of this component the scrap rate was around $30 \%$ and by consequence it influences the production costs. Besides that, other items that were previously assembled should not be reused increasing the production problems.

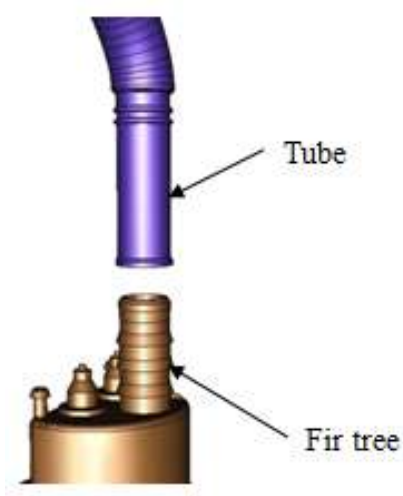

Figure 2. Interface evaluated between tube and fir tree

Two failure modes were observed during all assembly process (note that can exist more failure modes than these described on this paper; however during the study only these two were observed): 
1) Bend of tube during press-in process

2) The tube does not assemble completely
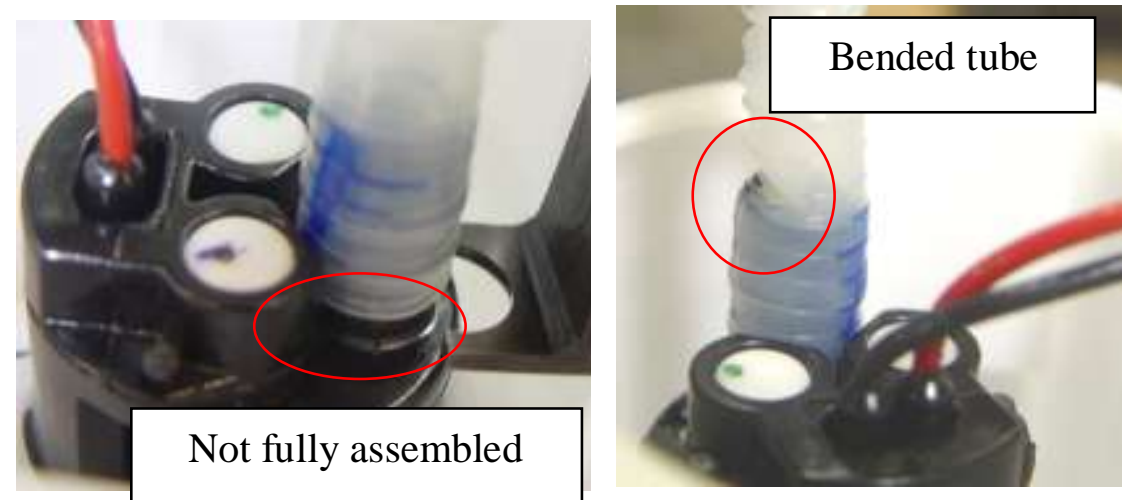

Figure 3. Failure modes: bended tube and tube out of specification

Based on failure modes, it was used the Ishikawa methodology to determine the factors that should be evaluated in order to minimize the scrap rate.

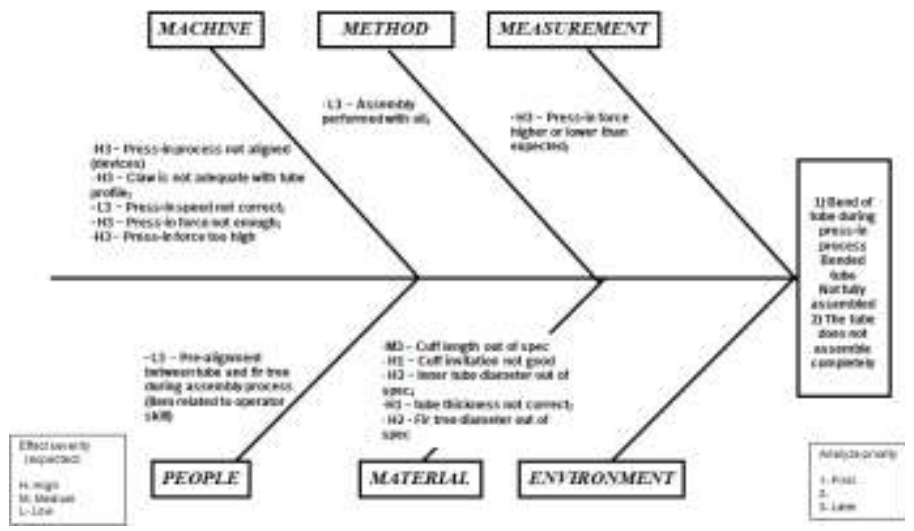

Figure 4. Ishikawa methodology for press-in process

According to the analysis it was observed that tube design could be improved. It is important mention that the focus on this paper is evaluate only design with CAE tool. Other factors can also be improved but they are not part of the study scope. Then, it was used a DOE method to evaluate what are the factors that are most important during an assembly process.

Six factors in 2 levels were determined (factorial design) for tube evaluation. 


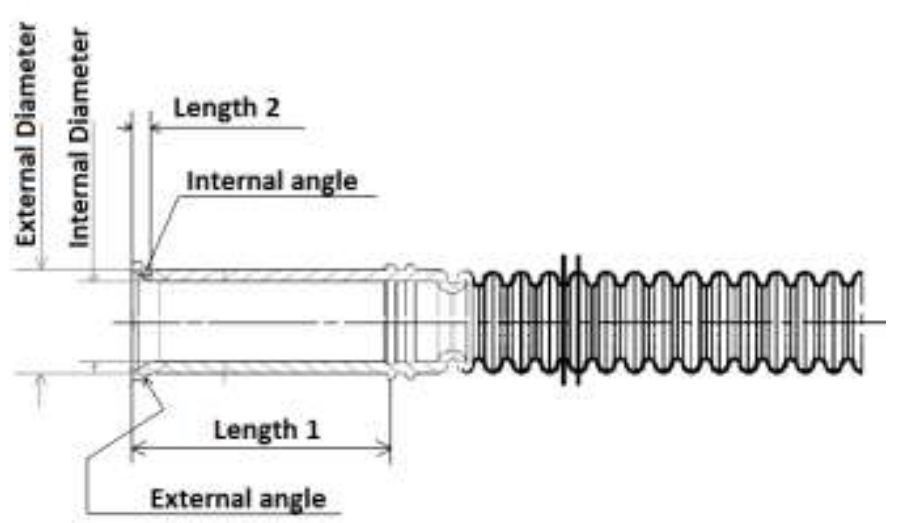

Figure 5. Factors from tubes

\begin{tabular}{|c|c|c|c|c|c|c|}
\hline & 1 & 2 & 3 & 4 & 5 & 6 \\
\hline 5ample (A) & Length 1 & External Dia. & Internal Dia. & Externat Angle & Intemal Angie & Length 2 \\
\hline 34 & Min & Max & Min & Min & Max & Min \\
\hline 35 & Min & $\operatorname{Max}$ & Min & Min & Min & Max. \\
\hline 37 & Min & Max & Min & Max & $\operatorname{Min}$ & Min \\
\hline 40 & Min & Max & Min & Max & Max & Max \\
\hline 41 & Min & Max & $\operatorname{Max}$ & Min & $\operatorname{Min}$ & Min \\
\hline 44 & Min & Max & $\operatorname{Max}$ & $\operatorname{Min}$ & Max & Max \\
\hline 46 & Min & Max & $\operatorname{Max}$ & Max & $\operatorname{Max}$ & Min \\
\hline 47. & Min & Max & $\operatorname{Max}$ & $\operatorname{Max}$ & Min & $\operatorname{Max}$ \\
\hline 49 & Min & Min & Min & Min & Min & Min \\
\hline 52 & Min & Min & Min & $\operatorname{Min}$ & Max & Max \\
\hline 54 & Min & Min & Min & Max & Max & Min \\
\hline 55 & Min & Min & Min & Max & Min & Max \\
\hline 58 & Min & Min & Max & $\operatorname{Min}$ & Max & Min \\
\hline 39 & Min & Min & Max & Min & Min & Max \\
\hline 61 & Min & Min & Max & $\operatorname{Max}$ & Min & Min \\
\hline 63 & Min & Min & Max & Max & Min & Max \\
\hline 64 & Min & Min & $\operatorname{Max}$ & $\operatorname{Max}$ & $\operatorname{Max}$ & $\operatorname{Max}$ \\
\hline 65 & Max & Max & Min & Min & Min & Min \\
\hline 68 & Max & Max & Min & Min & Max & Max \\
\hline 70 & $\operatorname{Max}$ & Max & Min & Max & Max & Min \\
\hline 71 & Max & Max & Min & $\operatorname{Max}$ & Min & Max \\
\hline 74 & Max & Max & Max & Min & Max & Min \\
\hline 75 & $\operatorname{Max}$ & Max & $\operatorname{Max}$ & Min & Min & Max \\
\hline 77 & Max & $\operatorname{Max}$ & Max & $\operatorname{Max}$ & Min & Min \\
\hline 80 & Max & $\operatorname{Max}$ & $\operatorname{Max}$ & $\operatorname{Max} x$ & $\operatorname{Max}$ & $\operatorname{Max}$ \\
\hline 81 & $\operatorname{Max}$ & Min & Min & Min & Min & Man \\
\hline 82 & Max & Min & Min & Min & Max & Min \\
\hline 83 & $\operatorname{Max}$ & Min & Min & Min & Min & Max \\
\hline 85 & Max & Min & $\operatorname{Min}$ & Max & Min & Min \\
\hline 85 & Max & Min & Min & Max & Mar & Max \\
\hline 92 & $\operatorname{Max}$ & Min & $\operatorname{Max}$ & $\operatorname{Min}$ & $\operatorname{Max}$ & Max \\
\hline 94 & $\operatorname{Max}$ & Min & $\operatorname{Max}$ & Max & $\operatorname{Max}$ & Min \\
\hline
\end{tabular}

Figure 6. Factors, levels values and samples used on evaluation

However, as there were many factors and it is known that is too difficult to obtain samples for all the levels, it was chosen that a CAE tool would be very useful for this design/assembly analysis.

\section{RESULTS}

The most important thing on result is if tube can be assembled or not. 


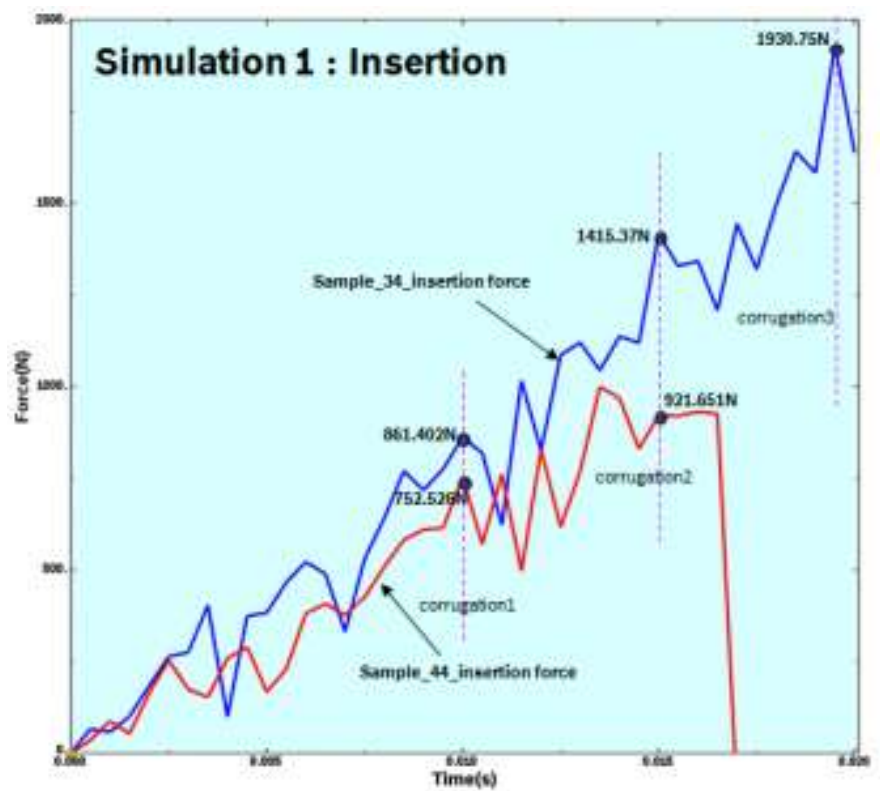

Figure 7. Simulation graph for two different samples

It is possible read from figure 7 that blue curve represents a correct assembly without any anomaly but red one shows that the tube bended during the assembly process. 


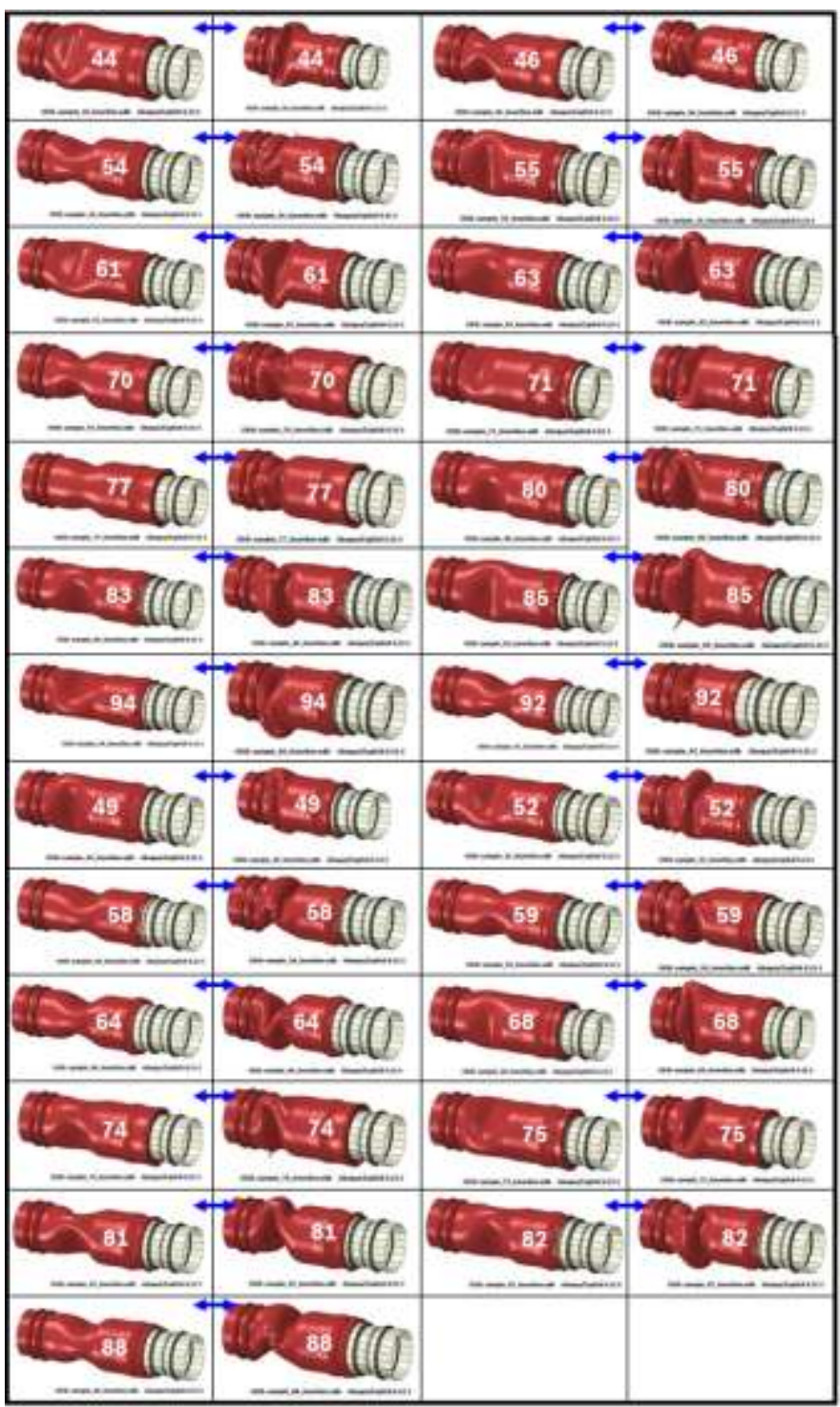

Figure 8. Samples that fail during the insertion are shown here. The failure mode of each failing tube is shown with two pictures. Picture 1 (left side) showing the unstable behaviour initiation stage and picture 2 (right side) shows the final mode of deformation during insertion.

Based on all results and using a Pareto analysis, it is possible evaluate which factors from the 6 ones defined on the beginning of study are most important in order to improve the tube assembly. 


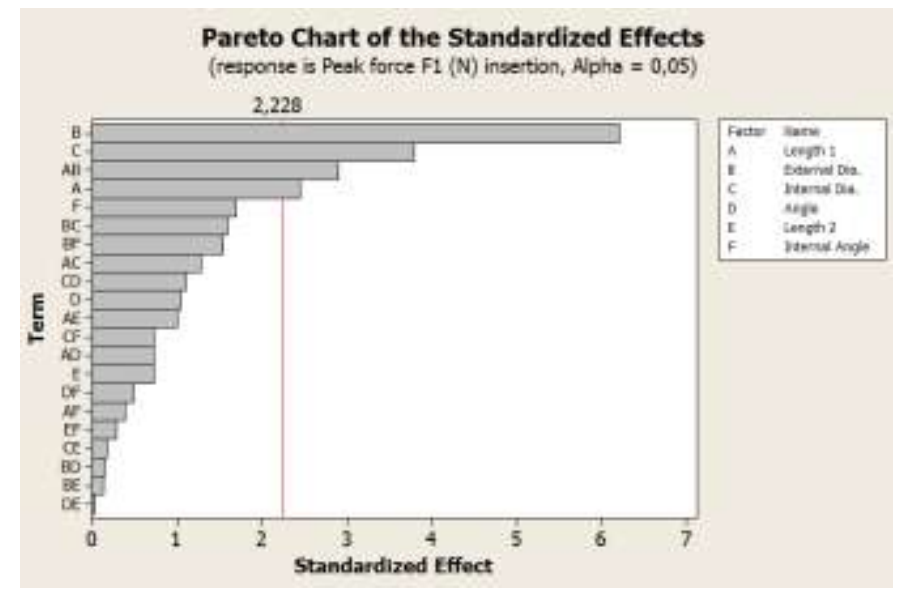

Figure 9.Pareto after simulation

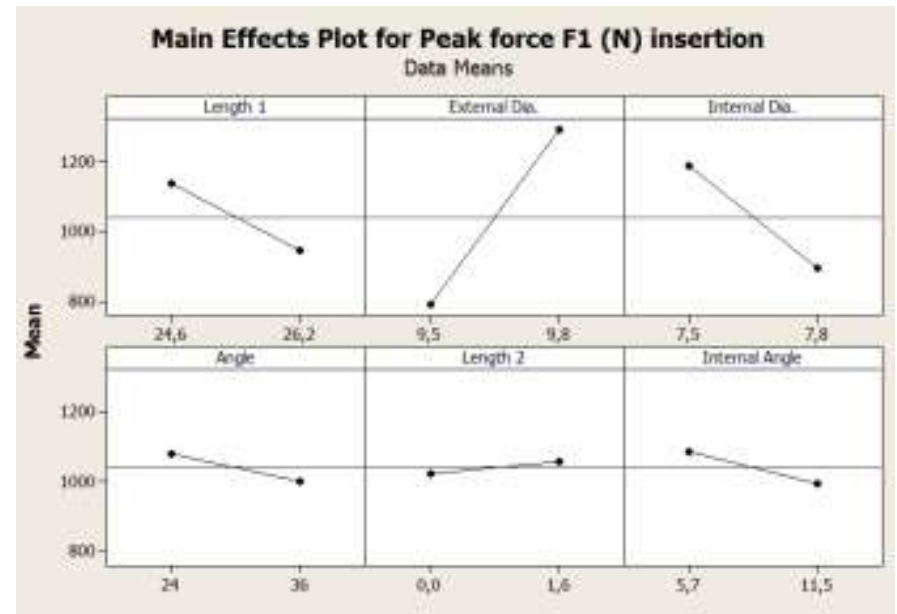

Figure 10.Main Effects Plots from simulation

The simulation results show that there are 3 main factors affecting the assembly process. In this case, it is important mention that design decision cannot be done only evaluating the graphs. A discussion with tube supplier is also necessary in order to make the whole process feasible.

\section{SUMMARY/CONCLUSIONS}

In summary, based on main factors that were raised from DOE and the boundaries from tube supplier's process, the tube design was changed. 


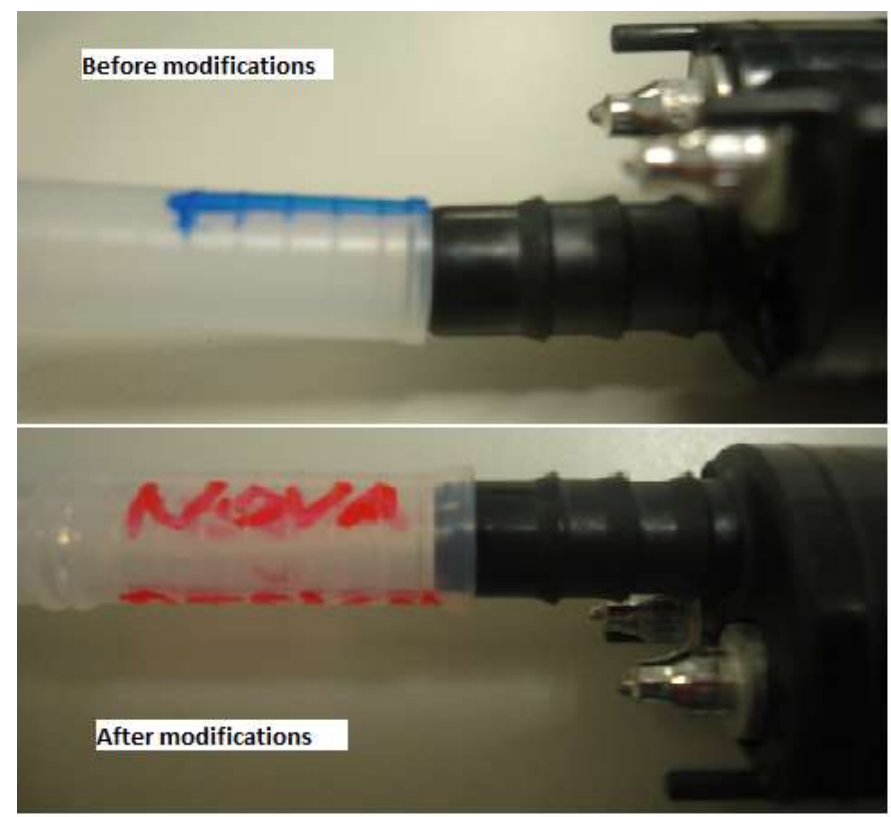

Figure 11. Pre-assembly stage (before press in process)

As a conclusion, the scrap rate that was around $30 \%$ decreased to $0.3 \%$ because the correct factors were adjusted. It means that one of the Lean principles was respected: cost reduction totally aligned with decrease of production waste.

\section{CONTACT INFORMATION}

Nathan Fonte Boa

Robert Bosch Ltda

Engenharia de Desenvolvimento de Produto

Gasoline Systems (GS-FS/ENG11-LA)

13065-900 Campinas

Brazil

Tel. +55(19)2103-1232

Marcos Paulo del Passo

Robert Bosch Ltda

Engenharia de teste de Produto

Gasoline Systems (GS-ETC/LA)

13065-900 Campinas

Brazil

Tel. +55(19)2103-1897

\section{REFERENCES}

[1] DENNIS, P. Produção Lean Simplificada. 2 ed. Porto Alegre: Bookman, 2008. 190 p.

[2] Robert Bosch internal documents 